\title{
RETURN VISITS TO THE EMERGENCY DEPARTMENT
}

\author{
Benjamin Lerman, MD, ${ }^{\star} \dagger$ and Michael S. Kobernick, MD $\ddagger$ \\ * Resident. Emergency Medicine. University of Cincinnati \\ $\ddagger$ Attending Emergency Physician, William Beaumont Hospital, Clinical Instructor, University of Michigan \\ Reprint address: Michael S. Kobernick, MD. William Beaumont Hospital. Department of Emergency \\ Medicine, 3601 Wost Thirteen Mile Road. Royal Oak, Ml 48072
}

\begin{abstract}
$\square$ Abstract - A persistent problem for emergency physicians is the patient who returns unscheduled to the emergency department with a problem that either has not improved or has worsened. The purpose of this study was to evaluate the frequency of revisits and the nature of the problems. All patients returning within 72 hours of their initial visit were entered into the study. The charts were evaluated for classification of problem, unavoidable $v$ avoidable returns, and errors in medical care or patient education. Of the 64,336 patients seen during the study, 255 returned within 72 hours. Eighty-three $(\mathbf{3 2 . 5 \%})$ of the returns were found to be avoidable with better patient education or medical care on the initial visit. The revisit population is a high-risk group of patients who should be approached carcfully by emergency physicians.
\end{abstract}

Keywords - emergency department return visits; quality assurance; repeat visits; revisits

\section{Introduction}

A persistent problem for emergency physicians are the patients who return unscheduled to the emergency department with an

†This work was done during Dr Lerman's senior year of Medical School at the University of Michigan. illness that either has not improved or has worsened. These patients are frequently dissatisfied and represent a medicolegal high-risk group. A recent ACEP publication calls these patients "red-flag patients," asserting that "many of the cases that end up in suit show that the patient has been to the emergency department more than once for the same condition." The purpose of this study was to determine the frequency of revisits, types of illnesses that return, and if any of the visits could have been avoided by improved patient education and better medical care.

\section{Methods}

From March 1984 through February 1985, clerks in the billing office of the William Beaumont Hospital Emergency Department (ED) were instructed to photocopy the records of any patient seen twice within 72 hours. These paired charts were then reviewed by the authors. Scheduled returns, visits greater than 72 hours apart, and patients not seen on their initial visit by ED physicians were eliminated. The remaining memos were sorted into 11 arbitrary diagnostic groups, as listed in Table 1. The total number of visits to the ED in

Original Contributions presents articles of interest to both academic and practicing physicians. This section of JEM is coordinated by John A. Marx, MD, of Denver General Hospital. 
Table 1. Revisits Per Diagnostic Category

\begin{tabular}{lcr}
\hline $\begin{array}{l}\text { Diagnostic } \\
\text { Group }\end{array}$ & No. of Visits & $\%$ \\
\hline Trauma & 65 & 25.5 \\
Infectious & 33 & 12.9 \\
Miscellaneous & 28 & 11.0 \\
Gastrointestinal & 27 & 10.6 \\
Epistaxis & 19 & 7.5 \\
Ob-gyn & 19 & 7.5 \\
Neurological & 16 & 6.3 \\
Pulmonary & 15 & 5.9 \\
Allergy & 14 & 5.5 \\
Urinary calculi & 11 & 4.3 \\
Psychiatric & 8 & 3.1 \\
Totals & & \\
\hline
\end{tabular}

each of the 11 categories during the final month of the study period was made using the discharge diagnoses recorded on the ED's daily log. These figures were extrapolated to estimate the total number of visits in each category for the year. This number was then divided into the total number of revisits for the year, yielding an estimate of the percentage returning in each category (Table 2). An attempt was made to describe the revisit as unavoidable or avoidable (Table 3 ), the latter category being further divided into problems of patient education and problems of inappropriate care (Iàble 4).

\section{Category Definitions}

The 11 diagnostic categories were allergic, epistaxis, gastrointestinal, infectious, neurologic, ob/gyn, pulmonary, psychiatric, traumatic, urinary calculi, and miscellaneous. When two diagnoses appeared, an arbitary decision was made as to which was the primary problem and the case was so classified. When a single diagnosis might fall in either of two categories, an arbitrary choice was made and consistently applied (eg, pelvic inflammatory disease was considered infectious rather than ob/gyn).

The cases were also classified as follows:
Table 2. Returns Projected for 1 Year *

\begin{tabular}{lrc}
\hline Diagnostic Group & $\begin{array}{c}\text { Projected } \\
\text { Total Visits/Yr }\end{array}$ & \% Returning \\
\hline Urinary calculi & 404 & 2.7 \\
Epistaxis & 834 & 7.3 \\
Ob-gyn & 1512 & 1.25 \\
Pulmonary & 1421 & 1.05 \\
Psychiatric & 1017 & 0.78 \\
Neurological & 3077 & 0.51 \\
Gastrointestinal & 5438 & 0.5 \\
Infectious & 9180 & 0.35 \\
Trauma & 22,937 & 0.28 \\
Allergy & 5006 & 0.27 \\
Miscellaneous & 13,353 & 0.2 \\
& & \\
Totals & 64,179 & 0.4 \\
\hline
\end{tabular}

*February totals multiplied by 365 days in a year divided by 28 days to equal a factor 13.04 to correct for the shorter month. The actual visits for this period was 64,336 .

1. Unavoidable. The return visit was related but did not seem to be avoidable either by different care or further patient education on the first visit (eg, a wound check). This category also includes six cases in which the complete records were unavailable or illegible and eight cases in which the subsequent visit was apparently unrelated to the first.

2. Avoidable. Comprised the following two categories.

a. Patient education. The subsequent visit would likely have been avoided by a more knowledgeable patient. This was applied to cases where the patient's actions exacerbated his condition, or in which the patient returned despite a predictable, uneventful course that required no change in plan.

b. Inappropriate. The subsequent visit would likely have been avoided by more definitive diagnostic or therapeutic efforts during the first visit (eg, omitting urinalysis from a sepsis evaluation). Deficiencies that had no bearing on the return visit were excluded, as were errors that could only be appreciated based on the subsequent course. 
Table 3. Unavoidable/Avoidable Revisits

\begin{tabular}{lcc}
\hline Diagnostic Group & Unavoidable (\%) & Avoidable (\%) \\
\hline Allergy & $7(50.0 \%)$ & $7(50.0 \%)$ \\
Epistaxis & $14(73.7)^{\star}$ & $5(26.3)$ \\
Gastrointestinal & $20(74.1)$ & $7(25.9)$ \\
Infectious & $20(60.6)$ & $13(39.4)$ \\
Neurological & $8(50.0)$ & $8(50.0)$ \\
Ob-gyn & $18(94.7)^{\star}$ & $1(5.3)$ \\
Pulmonary & $14(93.3)^{\star}$ & $1(6.7)$ \\
Psychiatric & $3(37.5)$ & $5(62.5)$ \\
Trauma & $37(56.9)$ & $28(43.1)$ \\
Urinary calculi & $9(81.8)^{\star}$ & $2(18.2)$ \\
Miscellaneous & $22(78.6)$ & $6(21.4)$ \\
& & $83(32.5)$ \\
Totals & $172(67.5)$ &
\end{tabular}

*Highest frequency of returns (see text).

Table 4. Causes of Avoidable Revisits

\begin{tabular}{lcc}
\hline Diagnostic Group & $\begin{array}{c}\text { Patient } \\
\text { Education (\%) }\end{array}$ & $\begin{array}{c}\text { Inappropriate } \\
\text { Care (\%) }\end{array}$ \\
\hline Allergy & $3(42.9)$ & $4(57.1)$ \\
Epistaxis & $4(80.0)$ & $1(20.0)$ \\
Gastrointestinal & $2(28.6)$ & $5(71.4)$ \\
Infectious & $6(46.2)$ & $7(53.8)$ \\
Neurological & $4(50.0)$ & $4(50.0)$ \\
Ob-gyn & $0(0.0)$ & $1(100.0)$ \\
Pulmonary & $1(100.0)$ & $0(0.0)$ \\
Psychiatric & $0(0.0)$ & $5(100.0)$ \\
Trauma & $13(46.4)$ & $15(53.6)$ \\
Urinary calculi & $2(100.0)$ & $0(0.0)$ \\
Miscellaneous & $3(50.0)$ & $3(50.0)$ \\
& $38(45.8)$ & $45(54.2)$ \\
Totals & &
\end{tabular}

\section{Results}

A total of 250 patients were seen more than once in a 72-hour period from March 1984 through February 1985. Table 1 shows the rank order of returns in each category and their percent. Traumatic were most common, followed by infectious (upper respiratory tract infection most often), miscellaneous, and gastrointestinal (primarily abdominal pain). The diannoses included under miscellaneous WL: : chest pain (7), lower back pain (5), palpitation/dysthyrhmia (3); urinary retention (2), eye pain, hematuria, hemophilia, cervical pain, laryngeal abrasion, frostbite, false aneurysm, thrombocytopenia, and check feeding tube (one each).
Within some categories one or two conditions accounted for the bulk of the cases. Specifically, neurologic consisted mostly of headaches and seizures. Ob/gyn was most commonly threatened abortions, and pulmonary was exclusively asthma and chronic obstructive pulmonary disease (COPD). Table 2 shows the rank order of the revisits when they are compared with the total number of visits projected in each category for the entire year. Problems with a comparatively high rate of return include urinary calculi $(2.7 \%)$, epistaxis $(2.3 \%)$, ob/gyn $(1.25 \%)$, and pulmonary $(1.05 \%)$. The remaining groups are in the less than $1 \%$ range.

The revisits are classified as avoidable or unavoidable in (Table 3). The majority 
$(67.5 \%)$ of the returns were unavoidable. The groups with the highest frequency of return (urinary calculi, epistaxis, ob/gyn, and pulmonary) have the highest frequency of unavoidable revisits. The avoidable revisits are scattered throughout the groups. Table 4 divides the avoidable revisits into those caused by patient education errors and those due to inappropriate care. Forty-five of the $255(17.6 \%)$ revisits represented cases of medical error. Nine "inappropriate" cases consisted of patients recalled following reread of a radiograph. All except one of these were traumatic cases. Thirty-eight $(15 \%)$ had poor patient education. No complaints, lawsuits, or life-threatening morbidity were found in this group.

\section{Discussion}

The limitations of a chart review study such as this one are numerous: incomplete and illegible records, a classification system that does not match the specialty, in- complete identification of cases, and, most importantly, the bias of an unblinded reviewer in judging the care rendered retrospectively. Nonetheless, the results of this study do have significant implications. The revisit population is a significant source of patients whose medical care was not appropriate. In this study $17 \%$ of the group were inappropriately treated. Although no lawsuits were generated, this is a group of patients with a high probability of medical care error. Quality Assurance efforts such as those suggested in the Illinois ACEP handbook ${ }^{2}$, need to be encouraged. Patient education is important, and $15 \%$ of the revisits would have been avoided by better education. This may also have an impact upon public relations in the emergency department. A department with a high revisit population as a symptom of poor patient education may notice a decline in its image. This article confirms that any patient returning within 72 hours of their initial visit represents a "red-flag" patient, and emergency physicians should continue to approach this patient population carefully.

\section{REFERENCES}

1. Rogers JT: Risk Management in the Emergency De partment. Dallas, ACEP Publication 1985, pp 7-8.
2. Illinois ACEP: Quality Assessment in the Emergency Department. Chicago, 1984. 